\title{
PROPUESTAS DE EJERCICIOS DE SIMULACIÓN PARA LA DIDÁCTICA DE LA INTERPRETACIÓN TELEFÓNICA
}

\author{
María Magdalena Fernández Pérez \\ mmfernan@ull.es \\ Universidad de La Laguna
}

\section{Resumen}

La interpretación telefónica (IT) es una variedad de interpretación remota cuya presencia no hace sino aumentar en los servicios públicos de numerosos países, entre ellos España. Si bien se lleva a cabo normalmente en modalidad bilateral o consecutiva dialógica, el ejercicio de la IT requiere la adquisición por parte del estudiante de una serie de destrezas específicas derivadas de sus características distintivas (Rosenberg 2007).

El role-play o ejercicio de simulación, una de las herramientas metodológicas más utilizadas en la formación en interpretación de enlace, constituye un instrumento clave en la didáctica de la IT. El presente trabajo tiene como objetivo identificar los diferentes elementos que debe incorporar el ejercicio de simulacro en sus diferentes variedades (guionizado o improvisado) para contribuir al desarrollo de las destrezas del intérprete telefónico.

\begin{abstract}
"Designing role-play models for Telephone Interpreting training"

Telephone Interpreting (TI) is a variety of remote interpreting which is increasingly present in public services of many countries such as Spain. Although it is usually carried out in liaison or bilateral interpreting, TI requires trainees to develop a number of specific skills due to its specificities (Rosenberg 2007).

As one of the most used methodological tools in bilateral interpreting, role-plays have also become a key instrument in TI training. This paper aims at identifying the main elements that a role-play (either scripted or improvised) should include to help developing TI specific skills.
\end{abstract}


Palabras clave: Interpretación para los servicios públicos. Interpretación telefónica. Destrezas específicas. Traducción y coordinación. Ejercicio de simulación.

Keywords: Public service interpreting. Telephone interpreting. Specific skills. Translating and coordinating. Role-play.

Manuscript received on February 15, 2013 and accepted for publication on September $25,2013$. 


\section{La interpretación telefónica: características específicas}

La interpretación telefónica (IT) es una modalidad de interpretación remota que se realiza a través del teléfono. En palabras de Nataly Kelly (2007: 18), "Telephone Interpreting is provided when an interpreter, who is usually based in a remote location, provides interpretation via telephone for two individuals who do not speak the same language".

Aunque en países como Estados Unidos no es extraño el uso de la interpretación simultánea por teléfono, especialmente en el ámbito judicial (NAJIT 2009), la modalidad más utilizada en la IT es la interpretación bilateral (IB) o de enlace, por lo que son muchas las similitudes entre la IT y la interpretación presencial cuando se lleva a cabo en esta modalidad. No obstante, la utilización del teléfono como canal instrumental convierte a la IT en un tipo de interpretación con características distintivas (Rosenberg 2007: 75): la ausencia de información visual; la sobreexposición del intérprete en un breve lapso de tiempo a un gran número de usuarios procedentes de diferentes lugares, culturas, ámbitos profesionales o variantes dialectales; y el equipo técnico utilizado, que determina el tipo de llamada y las estrategias adoptadas por el intérprete para coordinar el encuentro correctamente. ${ }^{1}$ A partir de estos rasgos diferenciadores, se han identificado una serie de destrezas necesarias para el ejercicio profesional de la IT (Fernández Pérez 2012), que se han clasificado de acuerdo con la doble función del intérprete para los servicios públicos descrita por Wadensjö (1998: 105), la de traducir y coordinar. La tarea de coordinación requiere el dominio de diversas destrezas, como son la gestión del inicio del encuentro y de su finalización, la gestión de los turnos de palabra y la realización de interrupciones por parte del intérprete. Por otro

1. Rosenberg (2007: 72-73) clasifica los tipos de llamadas que se producen en la IT en tres tipos: llamada a tres (three-way telephone conversation), en la cual cada uno de los participantes se encuentra en una ubicación física diferente; telephone passing, en la cual el intérprete se encuentra en un lugar distinto de los usuarios, quienes se pasan el auricular el uno al otro y por último las llamadas con manos libres (speakerphone conversation), en las cuales el intérprete se encuentra en una ubicación alejada y se comunica con las partes a través de este dispositivo. 
lado, las destrezas específicas del intérprete telefónico como traductor del encuentro consisten en la utilización de la toma de notas adaptada al uso del teléfono como medio de comunicación. Asimismo, se han identificado otras dos destrezas relacionadas con ambas funciones: el dominio de los elementos prosódicos y la utilización de la primera y la tercera persona en la reformulación de los enunciados. En este trabajo nos centraremos en la utilización de los ejercicios de simulacro para el desarrollo de las destrezas relacionadas con la coordinación del encuentro, así como el dominio de la prosodia, por tratarse de un aspecto poco estudiado en el ámbito de la IB.

\section{Los ejercicios de simulación como herramienta didáctica de la IT}

El ejercicio de simulación o role-play es una de las herramientas metodológicas más utilizadas en la enseñanza de la IB y por extensión, de la interpretación en los servicios públicos (ISP), donde, como se ha mencionado, continúa siendo la modalidad más empleada. La simulación es una actividad didáctica que pretende colocar al estudiante en situaciones lo más similares posible a encuentros reales en los que tiene que mediar como intérprete. De esta forma, permite aplicar e interiorizar de manera práctica los conocimientos teóricos adquiridos previamente y anticipar obstáculos que con toda probabilidad se le presentarán al intérprete en el desempeño de su labor, así como desarrollar las estrategias adecuadas para superarlos. Fowler (2007: 256-257) destaca que los ejercicios de simulación no solo resultan útiles cuando el estudiante desempeña el papel de intérprete, sino también cuando observa a sus compañeros interpretar, es decir, como parte del proceso de autoevaluación y evaluación entre pares.

Students need a great deal of practice in observing their peers as they interpret if they are to learn from one another. In general, the more opportunities for observation of interpreted role-plays they have, the more they will learn. When students have had experience in debriefing their peers, their ability to assess themselves is greatly improved. (Fowler 2007: 256-257)

Al tratarse de una actividad en la que participan varias personas (tres como mínimo en el caso de la didáctica de la IB), el ejercicio de simulación funciona, tal como señala Solís, como "un juego cooperativo en el que todos sus participantes son actores y espectadores en algún momento del proceso" y en el cual "cada integrante constituye una pieza significativa y constitutiva del resultado que se persigue". La utilización de los role plays parte de la premisa de que al recrear una vivencia, "mejora la capacidad crítica, analítica y reflexiva de los estudiantes, así como su habilidad para resolver conflictos" (Solís 2011). A efectos de este trabajo, nos referiremos a ejercicios de simulación destinados 
a la formación de intérpretes telefónicos, elaborados por formadores y representados e interpretados por estudiantes.

\subsection{Variedades de ejercicios de simulación en la formación de intérpretes}

Los ejercicios de simulación admiten una serie de variaciones en su diseño. Básicamente, pueden representarse mediante la lectura de un guión previamente redactado o improvisando los parlamentos a partir de unas directrices proporcionadas con antelación. Cada uno de estos tipos de role-plays permite trabajar la adquisición de diferentes destrezas por parte del intérprete en formación (Fernández Pérez 2011: 164).

De forma general, se puede afirmar que los ejercicios guionizados cuentan con la ventaja de que el docente ejerce un mayor control sobre la actividad, al diseñarla con unos objetivos de aprendizaje específicos en mente. Sin embargo, su representación suele resultar menos natural, lo que los hace menos apropiados para la adquisición de destrezas relacionadas con la coordinación de la interacción conversacional real, como la gestión de las interrupciones y del solapamiento de los turnos de palabra o el dominio de la prosodia. De acuerdo con Tebble, los role-plays guionizados...

[...] do not reflect the way people typically use spoken language with hesitations, false starts, inappropriate word choice; ungrammatical and incomplete utterances; rephrasing; auditor back channel responses; conversational repairs, and overlapping talk. (Tebble 2009: 205)

Incluso aunque el texto del role-play recoja rasgos propios del lenguaje hablado como los que menciona la autora, a los estudiantes que participan en el ejercicio como actores les resulta difícil reproducirlos con naturalidad. Las simulaciones guionizadas terminan por ser leídas más que oralizadas. Además, tal y como destaca Tebble, no siempre plasman fenómenos conversacionales que ponen en peligro la comunicación (interrupciones, solapamiento, etc.) o que, por el contrario, la alientan (elementos de confirmación, gestos para animar a continuar hablando, asentimiento con la cabeza, etc.). En consecuencia, el intérprete ve facilitada de manera artificial su labor como coordinador de la conversación. Por ello, si no se planifican y ejecutan de forma apropiada, los role-plays guionizados corren el riesgo de convertirse en meros ejercicios de transferencia lingüística.

En el caso de las simulaciones improvisadas, si bien no se rigen por la lectura de un guión escrito previamente, dicha improvisación casi nunca es total, sino que viene pautada en mayor o menor grado por el docente mediante una serie de instrucciones, de manera que la actividad cumpla un objetivo didáctico concreto. Este tipo de ejercicios sí permite reflejar de manera más 
fiel la realidad verbal de los encuentros dialógicos, y este es el motivo por el que Tebble apuesta por ellos en la formación de intérpretes para los servicios públicos, siempre que vayan acompañados de suficiente información previa sobre el encuentro, la cual "can potentially result in a higher quality of interpreting than if one concentrates only on trying to find equivalences in the other language" (Tebble 2009: 205).

Los role-plays improvisados son ejercicios cuya ejecución recae en mayor medida en los propios estudiantes-actores, por lo que el éxito del ejercicio dependerá en gran parte de la habilidad de improvisación y la naturalidad de estos al representar los diferentes papeles asignados. Debido a su naturaleza espontánea, las simulaciones improvisadas suelen constar, entre otras características, de una menor densidad conceptual y de intervenciones más breves. Por tanto, no resultan idóneos para desarrollar destrezas como el manejo de la terminología específica o la adquisición de una toma de notas eficaz (Fernández Pérez 2011: 165).

Teniendo en cuenta los rasgos generales de estos dos tipos de simulación, se podría concluir que ambas variedades contribuyen a desarrollar las diferentes destrezas interpretativas necesarias para el desempeño de la IT (Fernández Pérez 2011: 164).

\section{Modelos para el diseño de ejercicios de simulación}

En lo que se refiere a la elaboración de role-plays destinados tanto a la didáctica como al diseño de pruebas de acreditación y formación continua para intérpretes, Tebble (2009: 204) resalta la utilidad del modelo "SPEAKING" de Hymes (1974). En él se definen los componentes de la interacción lingüística, que serían, de manera resumida, los siguientes:

- El contexto y la escena, que se refieren a la dimensión física del encuentro (momento y lugar del evento discursivo) y la dimensión psicológica (por ejemplo, el estado de ánimo de los interlocutores).

- Los participantes (orador/emisor y oyente/receptor; en la IB cada participante desempeña ambos papeles).

- Los resultados u objetivos perseguidos.

- El contenido o tema tratado.

- El registro utilizado.

- Normas (la manera en que interaccionan los participantes; por ejemplo, si las interrupciones están permitidas o son socialmente aceptables).

- El tono adoptado o las características prosódicas del evento discursivo. 
- El canal de comunicación.

- El género o tipo de discurso.

Este modelo resulta de gran utilidad de cara al diseño de ejercicios de simulación para la formación de intérpretes telefónicos, al establecer de manera sistemática los elementos que caracterizan un encuentro comunicativo real. Puesto que la finalidad de los role-plays reside en representar situaciones lo más parecidas posible a la realidad profesional de la IT, sería conveniente que el docente incluyese estos elementos en las simulaciones utilizadas en el aula, pudiendo servir incluso de guía para su elaboración. Estos componentes pueden aparecer bien de manera explícita o implícita. En las simulaciones guionizadas, cabe indicar algunos de ellos al principio del ejercicio, a modo de introducción y antes de que comiencen los parlamentos de los interlocutores. También pueden aparecer integrados en dichos parlamentos mediante acotaciones, entre paréntesis o corchetes (para indicar, por ejemplo, el estado de ánimo de los participantes). Esta información va dirigida a los estudiantesactores, de modo que sepan darle al texto la entonación correspondiente. En los ejercicios improvisados, sin embargo, cuantos más datos previos sobre el encuentro se proporcionen, mayor será la facilidad con que los actores desarrollarán después sus parlamentos, si bien se corre el riesgo de perder parte de la espontaneidad que caracteriza el habla cotidiana.

Otro modelo que puede resultar de utilidad para la elaboración de ejercicios de simulación es el modelo de análisis textual orientado a la traducción propuesto por Nord (1991), donde distingue entre los elementos intratextuales y extratextuales presentes en los textos fuente. La lista de elementos extratextuales establecida por Nord permite al docente determinar qué elementos deben proporcionarse a los estudiantes-actores antes de la representación del role-play para que puedan desarrollar sus papeles. De este modo, se establece quién es el emisor y receptor de los enunciados; la intención con que se emiten los parlamentos; el medio o canal por el que tiene lugar la comunicación; el lugar y el momento en que se produce el encuentro; el motivo del mismo, y la función textual. Por otro lado, los factores intratextuales serían: tema, contenido, presuposiciones (entendidas como asunciones por parte de los participantes en el encuentro derivadas de su bagaje cultural), composición textual, elementos no verbales, léxico, estructura sintáctica de las frases y características suprasegmentales presentes en los textos. En la elaboración de una simulación improvisada para la formación de intérpretes de enlace, la mayoría de estos factores se corresponderían con elementos que aparecen a medida que se desarrolla el role-play, es decir, conforme los actores crean 
la situación comunicativa. El docente no puede incluirlos en las pautas proporcionadas previamente porque surgen de manera espontánea, fruto de la improvisación de los estudiantes-actores. Es el caso, por ejemplo, de la estructura sintáctica de las frases, los elementos no verbales o suprasegmentales. Otros, sin embargo, sí pueden ser proporcionados por el profesor a los actores antes de la representación del ejercicio, como el tema que se va a tratar en el encuentro, el léxico (bien sea parcialmente) e incluso las asunciones.

\section{El desarrollo de destrezas del intérprete telefónico a través de ejercicios de simulación}

El diseño de ejercicios de simulación debe venir guiado por las destrezas específicas de esta modalidad, expuestas en el apartado 1. En este trabajo se abordarán las relacionadas con la función de coordinación y el dominio de la prosodia.

\subsection{Gestión del inicio y presesión}

Esta destreza consiste en la obtención de información por parte del intérprete sobre diversos factores extratextuales del encuentro: el lugar donde se produce, el motivo que lo origina, así como datos sobre los participantes en el mismo (número, cultura de origen, sexo, edad...), lo cual conforma lo que en IT se denomina briefing humano. Asimismo, el intérprete debe informarse acerca del tipo de dispositivo con el que se efectúa la llamada (manos libres, doble auricular, teléfono fijo o móvil) para poder indicar a los usuarios cómo se sucederán los turnos de palabra y anticipar posibles dificultades técnicas. Esto se conoce como briefing técnico y encuentra su correspondencia en el factor extratextual 'medio o canal' del modelo de Nord (1991: 57). La dificultad de recabar estos datos radica en el propio funcionamiento del servicio. En muchos países como España, el intérprete trabaja para una agencia que proporciona IT a diversos organismos de ámbitos muy diferentes (hospitales, fuerzas y cuerpos de seguridad del Estado, servicios sociales, entre otros). Cada vez que se produce una llamada, la empresa proveedora de IT conecta directamente al intérprete con la persona que demanda el servicio. Por regla general, el intérprete telefónico desconoce de qué entidad procede la llamada, por lo que la primera dificultad a la que se enfrenta es la de contextualizar el encuentro para recabar ambos tipos de briefing lo antes posible, durante las primeras intervenciones, de modo que el encuentro no se prolongue innecesariamente. Algunas agencias de IT recalcan que no es aconsejable que el intérprete formule preguntas directas sobre estos aspectos porque es posible 
que los propios participantes, al desconocer el funcionamiento de la IT, no sepan responder de manera precisa y ralenticen demasiado el inicio de la llamada. Para obtener el briefing, los intérpretes deben valerse de una serie de mecanismos de contextualización extraídos a partir de elementos textuales presentes al principio del encuentro. De cara a trabajar esta destreza en el aula, es importante que el docente introduzca dichos elementos en el texto de la simulación, de modo que el estudiante aprenda a identificarlos y utilizarlos para situar la entrevista.

En cuanto a la presesión, este es el momento en que el intérprete explica su papel a las partes e indica cómo se va a desarrollar el encuentro. Este procedimiento, habitual en la IB, se define como un protocolo que "helps to explain the dimensions of the interview to all parties and establishes the grounds upon which it is based" (Gentile et al. 1996: 44), al cual Tebble (1998: 27; 2003: 84) denomina contrato y Gentile et al. (1996: 44) briefing. La dificultad principal de llevarlo a cabo en la IT es que a menudo las partes no dan espacio al intérprete para que se presente, en ocasiones por desconocimiento sobre su papel y a veces por prisa o impaciencia. En estos casos, resulta especialmente útil potenciar la escucha activa y el dominio de los elementos prosódicos, de manera que se aproveche cualquier micro pausa para intervenir (Kelly 2008: 148,153). Asimismo, es imprescindible conocer los protocolos de la IT y aplicar el sentido común para adaptar la presentación al tiempo disponible (en una urgencia médica, por ejemplo, un simple "Soy su intérprete" será suficiente) (Kelly 2008: 149).

A continuación exponemos un extracto de simulación guionizada destinado a desarrollar esta destreza: ${ }^{2}$

Médico [Habla rápido, no da tiempo al intérprete a presentarse]: ¿Hola? ¿Hola, eres la intérprete? Mira, te llamo de aquí de la consulta, tengo aquí a esta paciente que no habla español, ¿tú le puedes traducir? Está la consulta llena de gente y no tengo mucho tiempo. Le dices que el niño está bien, que está bien, que se esté tranquila. Lo que pasa es que a ella se le ha diagnosticado diabetes gestacional, pero que es algo común, que lo normal es que desaparezca tras el embarazo. Bueno, te la paso y se lo dices.

2. Los fragmentos utilizados en este trabajo a modo de ejemplo han sido elaborados por la autora y extraídos de ejercicios de simulacro utilizados en el Experto en Traducción e Interpretación para los Servicios Comunitarios: Mediadores Lingüísticos, un posgrado en ISP de la Universidad de La Laguna. Los ejercicios completos podrán consultarse en los anexos I y II del presente trabajo. 
En este caso, las partes subrayadas se corresponden con elementos de contextualización de especial relevancia para el intérprete, puesto que facilitan información clave sobre la situación comunicativa: la llamada procede de una consulta médica (hospital o centro de salud); la paciente es una mujer, que además se encuentra embarazada. Asimismo, la expresión "Te la paso" proporciona al intérprete el briefing técnico, es decir, información sobre el tipo de dispositivo técnico que se está utilizando. En este caso, la comunicación se realiza a través de un teléfono con un solo auricular, lo cual previsiblemente dificultará la gestión de los turnos de palabra pero asegurará, en circunstancias normales, una mejor calidad de sonido.

En este fragmento, el médico no hace ninguna pausa que permita al intérprete explicar su papel y el funcionamiento del encuentro. En consecuencia, el estudiante-intérprete puede decidir interrumpirle o aprovechar la intervención del médico para recabar el briefing e intentar presentarse después, aun sea brevemente. Como se puede observar, la acotación entre corchetes o paréntesis describe la forma de actuar del médico y guía al estudiante-actor sobre cómo representar su papel.

Por otro lado, en un role-play sin guión, esta situación se reflejaría mediante una serie de acotaciones dirigidas únicamente a los actores para que puedan representar su papel. Según el modelo de Hymes (1974), se informaría de quiénes son los emisores, los objetivos perseguidos (informar a la paciente de su estado de salud), su estado psicológico, así como rasgos prosódicos del parlamento, como el tono y la velocidad de elocución. De esta manera, se anticipa un obstáculo que deberá resolver el estudiante-intérprete (valorar si es pertinente interrumpir al médico para gestionar la comunicación aun cuando este haya afirmado que tiene mucha prisa):

Al principio de la llamada, el médico se muestra impaciente y en consecuencia habla rápido, sin apenas pausas. No da tiempo a que el intérprete se presente y expone directamente lo que quiere que le transmita a la usuaria.

\subsection{Gestión de la finalización del encuentro}

Esta destreza consiste en la capacidad del intérprete telefónico para verificar si alguno de los participantes desea intervenir o añadir algo antes de dar por finalizada la entrevista. Este procedimiento cobra especial importancia en la IT, donde, una vez colgado el teléfono, es casi imposible reanudar la conversación con el mismo mediador lingüístico. Algo muy frecuente también es que 
uno de los participantes (habitualmente el proveedor del servicio) se marche antes de que el intérprete termine de transmitirle al otro usuario lo que acaba de decir, dejándole sin poder de réplica. El desarrollo de las destrezas necesarias para evitar que esto ocurra puede ponerse a prueba en ejercicios de simulacro tanto guionizados como improvisados.

(1) Simulación guionizada:

Enfermera: De acuerdo. Pues ya sabe, tiene que controlar el nivel de azúcar con el aparatito lo que le queda de embarazo. [Al intérprete] [...] Tú se lo traduces que me tengo que ir. Gracias, ¿ ¿eh? Hasta luego.

(2) Simulación improvisada:

[...] al final de la llamada, la enfermera se marcha precipitadamente sin confirmar que la paciente ha comprendido lo que se le ha dicho (cómo usar el glucómetro).

En ambos ejemplos, el alumno-intérprete se ve obligado a intervenir rápidamente para pedir a la enfermera que no se marche antes de confirmar que la paciente ha comprendido la información. Con estos simulacros guionizados o improvisados se pretende preparar al intérprete en formación para enfrentarse a situaciones de este tipo, enseñándole a reaccionar con diligencia e incluso a anticipar esta situación mediante la identificación de elementos prosódicos como la entonación o la velocidad de elocución, que pueden indicar un final de enunciado precipitado.

\subsection{Gestión de los turnos de palabra}

En su función de coordinador, el intérprete para los servicios públicos debe asegurar la alternancia de los turnos de palabra, rasgo esencial de la comunicación dialógica. Esta coordinación puede ejercerse de manera implícita o explícita (Wadensjö 1998: 109). La primera se produce cuando el intérprete se limita a traducir cada turno de palabra de manera fluida y la segunda, cuando interviene con voz propia o cuando invita a los usuarios a hablar o a dejar de hablar. La gestión de los turnos se ocupa de garantizar esta alternancia de intervenciones por parte de los diferentes interlocutores mediante la distribución de los turnos de habla y además, de restablecer dichos turnos siempre que se produzca una ruptura de los mismos por fenómenos conversacionales 
como el solapamiento de intervenciones o la interrupción por parte de uno de los usuarios, entre otros.

En el caso de la IT, la confusión causada por la ausencia de un marco físico común hace que los usuarios dependan del intérprete para saber cuándo hablar, especialmente en las llamadas a tres, donde los participantes están en ubicaciones diferentes. Esto convierte la gestión de los turnos de palabra en una destreza si cabe más complicada. La principal herramienta del intérprete telefónico para gestionar las intervenciones es la prosodia, como afirma Couper-Kuhlen (2009: 178), de modo que se puedan, por ejemplo, identificar espacios de transición entre ideas (Schegloff 1996: 97) y aprovecharlos para cambiar de orador, forzando así el cambio de turno. De esta manera se puede encauzar de nuevo el diálogo tras un solapamiento o una conversación paralela que había empezado a esbozarse.

Para ejercitar esta destreza resultan más apropiadas las simulaciones improvisadas. Para ello el docente tendría que especificar a los actores en las pautas previas que estos deben interrumpirse al hablar. Sin embargo, aunque el resultado probablemente será más natural que a través de un ejercicio guionizado, no garantiza que los estudiantes lo lleven a cabo durante el ejercicio (por pudor, por ejemplo).

Por otra parte, trabajar esta destreza a través de simulaciones guionizadas resultaría harto complicado. Si el docente decidiese incluir conversaciones solapadas o interrupciones de intervenciones en el texto del role-play, sería necesaria una lectura previa o incluso la memorización del mismo por parte de los estudiantes-actores para representar el texto con naturalidad, lo que resta flexibilidad a su empleo en el aula.

En cualquiera de los dos casos, sería recomendable que uno de los actores de la simulación fuese el propio profesor, al menos durante las primeras actividades. Esto contribuiría a "romper el hielo" y que los estudiantes no se mostrasen vergonzosos o tímidos a la hora de representar su papel. También puede resultar de utilidad el mostrar grabaciones de encuentros mediados por un intérprete telefónico (reales o simulados) que puedan tomar como referencia.

\subsection{Realización de interrupciones por parte del intérprete}

En ocasiones, el intérprete para los servicios públicos se ve obligado a interrumpir la comunicación y dirigirse a los interlocutores con voz propia con una serie de propósitos. En un encuentro presencial, puede servirse del lenguaje corporal, como un gesto con la mano o una mirada. El intérprete telefónico, sin embargo, tan solo puede valerse del uso de los patrones prosódicos 
o del dominio de la propia voz para interrumpir. Esta dificultad, unida a lo complicado que resulta reconducir la alternancia de los turnos de palabra por teléfono, hace que en ocasiones los intérpretes telefónicos dejen pasar posibilidades de interrumpir que hubieran sido necesarias o facilitado su tarea.

En la IT, los motivos por los cuales un intérprete puede interrumpir son los siguientes (Fernández Pérez 2012: 81-95):

- Pedir aclaraciones, repeticiones o confirmaciones de ciertos segmentos o elementos de información.

- Gestionar la densidad textual.

- Gestionar los turnos de palabra cuando el intérprete es interrumpido sin haber finalizado su intervención o cuando se produce solapamiento en la conversación.

- Corregir errores de interpretación.

- Resolver problemas de índole técnica.

Esta destreza resulta muy compleja de desarrollar mediante ejercicios de simulacro, sean estos guionizados o improvisados, pues la necesidad de interrumpir surge con frecuencia de manera espontánea cuando el estudianteintérprete se enfrenta a determinadas dificultades. No obstante, sí se pueden elaborar ejercicios de simulación donde se creen situaciones que obliguen al estudiante-intérprete a interrumpir para gestionar la comunicación. De los motivos de interrupción antes expuestos, los más difíciles de provocar mediante role-plays son, como es lógico, los errores de interpretación; los restantes van a depender del dominio de la técnica de la IT por parte del alumno. Asimismo, es esencial determinar los objetivos de aprendizaje de cada ejercicio antes de su puesta en práctica. Por ejemplo, el docente, al diseñar el roleplay, puede incluir un parlamento largo y de cierta densidad textual. De esta forma, el estudiante-intérprete tendrá que cortar esa intervención en varias partes para no omitir información y transmitir el mensaje de manera precisa o para aclarar algún término o concepto desconocidos. Asimismo, gracias a la densidad textual, puede trabajarse más eficazmente la toma de notas, pues difícilmente el alumno-intérprete logrará retener todos los datos apoyándose únicamente en la memoria. Esta estrategia para trabajar las interrupciones es más difícil de aplicar en los ejercicios de simulación improvisados, ya que los estudiantes que normalmente actúan de interlocutores primarios encuentran complicado emitir parlamentos extensos, especialmente cuando el ejercicio gira alrededor de un tema o concepto que no les resulta familiar.

Un motivo de interrupción exclusivo de la IT son las dificultades derivadas del uso de la tecnología. La resolución de estos problemas sí puede 
trabajarse a través de ejercicios de simulacro, tanto guionizados como improvisados. Bastaría con que uno de los estudiantes-actores afirmase no oír bien al intérprete, el cual, previsiblemente, comprobará las posibles causas de la incidencia tras haber recabado el briefing técnico (por ejemplo, escasez de cobertura o ruido ambiente excesivo). En el caso de que la simulación siga un guión, tal vez sea necesario cierto grado de improvisación por parte de los actores en ese momento, ya que el intérprete les hará preguntas que no estaban previstas en el texto del ejercicio para intentar resolver el problema. El formador también deberá especificar en una acotación a qué se debe el fallo técnico, de modo que los actores puedan actuar con coherencia. Un aspecto importante es que los role-plays incluyan la utilización de los distintos dispositivos telefónicos (de forma simulada o usándolos realmente).

\subsection{Dominio de los elementos prosódicos}

Ya se ha mencionado la importancia de los elementos prosódicos dentro del proceso de escucha activa y, en consecuencia, para el correcto desarrollo de destrezas ya expuestas de la IT como la gestión del inicio y de la finalización del encuentro, la gestión de los turnos y la realización de interrupciones. En términos generales, se puede afirmar que el dominio de los patrones prosódicos de la comunicación dialógica facilita enormemente la función del intérprete telefónico como coordinador del encuentro: nos ofrece información sobre los participantes (sexo, edad, lugar de origen, estatus socioeconómico), nos permite anticipar el principio o el final de un enunciado o un cambio de tema, por citar tan solo algunas posibilidades (Fernández Pérez 2012: 117128). Por añadidura, la prosodia influye en el significado de los enunciados, alterándolo o tiñéndolo de matices. Este aspecto, a menudo desatendido por los intérpretes no profesionales (Hale 2004), ha demostrado ser fundamental, especialmente en ámbitos donde estos matices cobran especial relevancia, como puede ser el policial o judicial. De esta manera, el contenido pragmático de un enunciado puede no equivaler al contenido proposicional, en especial cuando dicho enunciado es emitido con miedo, nerviosismo, ironía, sarcasmo o enfado. Esto debe ser transmitido por el intérprete a través de los mismos elementos prosódicos que el orador original, evitando hacer juicios de valor, pero con el propósito de causar el mismo efecto en el receptor de ese enunciado. Entre los elementos prosódicos que deben ser abordados en una propuesta didáctica integral de la IT se encuentran la entonación, la velocidad de elocución, las pausas o el tono, entre otros. Se trata de una habilidad difícil de desarrollar, para la cual resultan de mayor utilidad las simulaciones improvisadas. La representación de estos componentes prosódicos a través 
de un simulacro guionizado implica que los alumnos que hagan las veces de actores deben contar con un gran dominio de su propia voz, al tiempo que se expresan con naturalidad, algo que no siempre se consigue y que constituye un esfuerzo adicional añadido. Por ello, en este caso son más recomendables los role-plays improvisados donde el docente ofrezca pautas muy específicas a los estudiantes-actores sobre el carácter o estado de ánimo de los interlocutores. Aun así, si se ejercita esta destreza con un ejercicio guionizado, es conveniente indicar al principio de cada intervención el componente psicológico mediante una acotación entre corchetes o paréntesis.

Paciente [sorprendida y asustada]: Diabetes?? How's that possible?? I don't drink, I don't smoke... Diabetes!!! I can't believe it! Is my baby OK? Please tell me the baby is OK!

\section{Conclusiones}

Los ejercicios de simulacro son una herramienta metodológica habitual en la formación de intérpretes en los servicios públicos. Sus diferentes variedades (guionizados o improvisados) permiten al formador diseñar la actividad según los objetivos de aprendizaje perseguidos en el aula. En principio podría deducirse que los role-plays improvisados permiten trabajar mejor las destrezas específicas del intérprete telefónico, relacionadas en su mayoría con la función de coordinación del encuentro, ya que este tipo de simulaciones reproducen más fielmente las conversaciones reales donde la comunicación se ve alterada debido a solapamientos, interrupciones, etc. Sin embargo, la utilización de guiones íntegramente redactados por el formador también sirve para adquirir determinadas destrezas, por lo que el uso alternado de ambos tipos de ejercicios en el aula podría ser recomendable. En todo caso, para formar a intérpretes telefónicos no bastará con modificar ligeramente los ejercicios de simulacro pensados para la IB presencial, sino que deberán diseñarse de acuerdo con las especificidades de la IT, que van más allá de la ausencia de información visual. Asimismo, a la hora de escenificar los role-plays, el formador de IT debe tener en cuenta las posibles dificultades o reticencia de los alumnos para representar un papel de manera verosímil, es decir, para actuar, si bien la experiencia demuestra que, tras el pudor inicial, los estudiantes acaban por llevar a cabo esta tarea de manera natural y fluida. 


\section{Referencias bibliográficas}

Couper-Kuhlen, Elizabeth. (2009) “Prosody." En: D’Hondt, Sigurd; JanOla Östman \& Jef Verschueren (eds.) 2009. The Pragmatics of Interaction. Amsterdam: John Benjamins, pp. 176-189.

FERnÁndez PÉREZ, María Magdalena. (2011) "Variedades de exercicios de roleplay como ferramenta didáctica na formación de intérpretes para os servizos públicos." En: Cruces Colado, Susana; Maribel del Pozo Triviño; Ana Luna Alonso \& Alberto Álvarez Lugrís (eds.) 2011. Traducir en la frontera. Granada: Atrio, pp. 161-169.

FERnÁndez PÉREZ, María Magdalena. (2012) Identificación de las destrezas de la interpretación telefónica. La Laguna: Universidad de La Laguna. Trabajo de investigación conducente al DEA inédito.

Fowler, Yvonne. (2007) "No More Role Plays, Please-We're British: Devising Workshops on Working through an Interpreter for Police, Social Workers and Probation Officers." Versión electrónica: <http://criticallink.org/wp-content/uploads/2011/08/CL2_Fowler.pdf.>

GEnTILE, Adolfo; Uldis Ozolins \& Mary Vasilakakos. (1996) Liaison Interpreting: A Handbook. Melbourne: Melbourne University Press.

Hale, Sandra. (2004) The Discourse of Court Interpreting. Amsterdam: John Benjamins.

Kelly, Nataly. (2007) "Telephone Interpreting in Health Care Settings: Some Commonly Asked Questions." The ATA Chronicle 36:6, pp.18-21.

Kelly, Nataly. (2008) Telephone Interpreting. A Comprehensive Guide to the Profession. Bloomington: Trafford Publishing.

HyMES, Dell. (1974) Foundations in Sociolinguistics. An Ethnographic Approach. Londres: Routledge.

Motos Teruel, Tomás. (2005) "Elementos para la creación de un texto dramático.”Revista Recre@rte 3. Versión electrónica: <http://www.iacat.com/revista/ recrearte/recrearte03/Motos/creacion_drama.htm>

Nord, Christiane. (1991) Text Analysis in Translation. Theory, Methodology, and Didactic Application of a Model for Translation-Oriented Text Analysis. Amsterdam: Rodopi B.V.

RosenberG, Brett Allen. (2007) "A Data Driven Analysis of Telephone Interpreting." En: Wadensjö, Cecilia; Brigitta Englund-Dimitrova \& AnnaLena Nilsson (eds.) 2004. The Critical Link 4: Interpreters in the Community. Selected Papers form the $2^{\text {nd }}$ International Conference on Interpreting in Legal, Health, and Social Service Settings, Stockholm, Sweden, 20-23 May 2004. Amsterdam: John Benjamins, pp. 65-76.

SCHEGLOFF, Emanuel. (1996) "Turn Organization: One Intersection of Grammar and Interaction.” En: Ochs, Elinor; Emanuel Schegloff \& Sandra Thompson 
(eds.) 1996. Interaction and Grammar. Cambridge: Cambridge University Press, pp. 52-133. Versión electrónica: <http://icar.univlyon2.fr/ecole_thematique/tranal_i/documents/org_tours/sche96_turn_organization.pdf [Consultado el 4 de junio de 2012]>

Solís, Mariana. (2011) "Role playing como herramienta de enseñanza." Reflexión académica en diseño y comunicación 13:19, pp. 70-71.

TebBle, Helen. (1998) Medical Interpreting. Improving Communication with your Patients. Victoria: Deaking University.

TEBBLE, Helen. (2009) "What can interpreters learn from discourse studies?" En: Hale, Sandra; Uldis Ozolins \& Ludmila Stern (eds.) 2009. The Critical Link 5: Quality in Interpreting: A Shared Responsibility. Amsterdam: John Benjamins, pp. 201-220.

VARIOS AUTORES. (2009) NAJIT Position Paper. Telephone Interpreting in Legal Settings. Versión electrónica: <http://www.najit.org/publications/ Telephone\%20Interpreting.pdf>

WAdENSJÖ, Cecilia. (1998) Interpreting as Interaction. Londres \& Nueva York: Longman.

\section{Anexo I}

Ejercicio de simulación guionizado

Modalidad: interpretación telefónica.

Contexto: Consulta médica.

Usuarios: Un médico, una enfermera y una paciente.

Motivo de la llamada: La paciente, una mujer de habla inglesa que se encuentra embarazada, es diagnosticada diabetes gestacional. Teme que haya podido afectar al feto y se encuentra preocupada. El médico y la enfermera pretenden explicar a la paciente las medidas que debe tomar para que no surjan complicaciones derivadas de esta dolencia. Ambos tienen prisa, por lo que se impacientarán si el intérprete no es rápido al trasladar el mensaje y tratarán de interrumpirle.

Médico [Habla rápido, no da tiempo al intérprete a presentarse]: ¿Hola? ¿Hola, eres la intérprete? Mira, te llamo de aquí de la consulta, tengo conmigo a esta paciente que no habla español, ¿tú le puedes traducir? Está la consulta llena de gente y no tengo mucho tiempo. Le dices que el niño está bien, que está bien, que se esté tranquila. Lo que pasa es que a ella se le ha diagnosticado 
diabetes gestacional, pero que es algo común, que lo normal es que desaparezca tras el embarazo. Bueno, te la paso y se lo dices.

Paciente [sorprendida y asustada]: Diabetes?? How's that possible?? I don't drink, I don't smoke... Diabetes!!! I can't believe it! Is my baby OK? Please tell me the baby is OK!

Médico: Que sí, que sí, [dirigiéndose al intérprete]. ¿Pero no le has explicado lo que le acabo de decir, que no es nada grave? [Adoptando un tono tranquilizador] Simplemente hemos visto que sus niveles de glucosa en sangre son demasiado altos. A ver, que en realidad es algo bastante común en embarazadas de más de 35 años, como es su caso, así que tampoco hay que asustarse sino simplemente cuidarse un poquito. ¿Vale?

Paciente: So the baby is not in danger, then?

Médico. No, mientras haga lo que le vamos a explicar no va a haber problema. Le cuento: tiene que hacer ejercicio moderado, caminar unos 30 minutos al día y hacer una tabla de ejercicios que le estoy enseñando [Al intérprete]. Viene con dibujos así que no hace falta que se lo traduzcas. Y también la vamos a mandar al nutricionista para que le haga una dieta. ¿Lo está entendiendo?

Paciente: That's OK, no problem about that. I used to do a lot of exercise before getting pregnant, anyway, so I'm in good shape.

Médico: Perfecto. Y ya por último (y esto es lo más incómodo, pero también lo más importante), tendrá que controlar el nivel de azúcar en la sangre ella misma con este aparatito, que es un glucómetro. [Al intérprete] Ya te paso a la enfermera y ella te explica cómo usarlo. Venga, hasta luego.

Enfermera: [Al intérprete] Hola, iestás ahí? Sí, mira, le voy a explicar a la señora cómo usar el glucómetro. A ver cómo hacemos porque si tú no lo puedes ver... [A la paciente] Bueno, es muy fácil. ¿Ve esta agujita? Con esto se pincha la punta del dedo y se saca una gota de sangre. Bueno, antes de pincharse el dedo tiene que lavarse bien las manos o limpiar el dedo con alcohol. Si usa alcohol tiene que dejarlo secar antes de sacar la sangre. Vale, entonces, después de pincharse coloca la muestra de sangre en esta tira y luego la inserta en el aparatito así como le estoy enseñando.

Paciente: Excuse me, but, do I really have to do this? I am a bit squeamish about blood, you know, just the thought of it makes me feel sick. I will do the 
exercises and follow a healthy diet, no sweets or anything. But no glucometer, please, I can't stand the sight of blood, even if it's my own! And I hate needles!

Enfermera: Vaya, no me diga. Bueno, yo le diría que tiene que acostumbrarse, es sólo una gotita de sangre de nada. Si no pídale a alguien que se lo haga, su marido o quien sea, porque además va a tener que repetir esto varias veces al día.

Paciente: [Suspira] Ok, if there's no choice... I'll see if I can manage. Thank you.

Enfermera: De acuerdo. Pues ya sabe, tiene que controlar el nivel de azúcar con el aparatito lo que le queda de embarazo. [Al intérprete] Le estoy dando una tabla con las medidas para que sepa cuándo el azúcar está bien y cuando está demasiado alto y también con las horas a las que tiene que usar el glucómetro. Tú se lo traduces que me tengo que ir. Gracias, ¿eh? Hasta luego.

\section{Anexo II}

Ejercicio de simulación improvisado

Modalidad: interpretación telefónica.

Usuarios: Un médico, una enfermera y una paciente de habla inglesa.

Tanto el médico como la enfermera tienen prisa, por lo que se impacientarán si el intérprete no es rápido al trasladar el mensaje y tratarán de interrumpirle. Hablan deprisa, aunque intentan mostrarse comprensivos con la paciente. Al principio de la llamada, el médico se muestra impaciente y en consecuencia habla rápido, sin apenas pausas. No da tiempo a que el intérprete se presente y expone directamente lo que quiere que le transmita a la usuaria. Asimismo, al final de la llamada, la enfermera se marcha precipitadamente sin confirmar que la paciente ha comprendido lo que se le ha dicho (cómo usar el glucómetro).

La paciente se encuentra preocupada.

Contexto: Una mujer de habla inglesa que se encuentra embarazada acude al médico para recibir los resultados de una prueba que se le ha realizado. El médico le comunica que padece diabetes gestacional, algo común en mujeres embarazadas.

La paciente teme que la dolencia haya podido causar daño al feto y se encuentra nerviosa. 
El médico le explica que el bebé no tiene por qué verse afectado, pero que deberá tomar una serie de precauciones: realizar una tabla de ejercicios diaria, caminar media hora y seguir una dieta que le proporcionará el nutricionista. Asimismo, deberá medir varias veces a diario el nivel de azúcar en la sangre con un glucómetro.

La enfermera le explicará el funcionamiento del mismo, que resumidamente consistirá en lo siguiente: en primer lugar, la paciente debe lavarse las manos o desinfectarlas con alcohol. En este último caso, hay que dejarlas secar antes de sacar la sangre. A continuación, se pincha con la lanceta del glucómetro la punta del dedo, se extrae una gota de sangre, se coloca la muestra en una tira y por último se inserta esta tira en el aparato, que indica el nivel de glucosa en una pequeña pantalla.

Este ejercicio puede ser representado inmediatamente o entregado con antelación a los estudiantes-actores para que preparen el tema alrededor del cual gira el motivo del encuentro (un diagnóstico de diabetes gestacional). En este último caso, se eliminaría del texto anterior las explicaciones sobre lo que es la diabetes gestacional, las instrucciones a la paciente y la explicación del uso del glucómetro. En su lugar, sería útil realizar con los actores un ejercicio de anticipación antes de la representación de la simulación, en el que el estudiante-intérprete no estaría presente a fin de reflejar la realidad del ejercicio de la IT (en una situación verídica, el intérprete telefónico no tendría forma de conocer con antelación el motivo de la llamada). 


\section{NOTA BIOGRÁFICA / BIONOTE}

María MAgdalena FeRnÁndeZ PéREZ es la coordinadora académica del Experto Universitario en Traducción e Interpretación para los Servicios Comunitarios (EUTISC), un posgrado de la Universidad de La Laguna. Asimismo, enseña interpretación de enlace (ámbito jurídico-administrativo y socio sanitario) en el EUTISC y consecutiva y simultánea en el Máster en Interpretación de Conferencias (MIC) de la ULL desde 2006. Trabaja como intérprete profesional autónoma en las Islas Canarias. Como doctoranda, su investigación se centra en la didáctica de la interpretación en los servicios públicos y la interpretación telefónica.

María Magdalena Fernández Pérez is the Academic Coordinator of the Experto Universitario en Traducción e Interpretación para los Servicios Comunitarios (EUTISC), a postgraduate course on Community Interpreting at the University of La Laguna (Tenerife, Spain). She teaches liaison interpreting (applied to both healthcare and legal settings) at the EUTISC and consecutive and simultaneous interpreting at the Masters in Conference Interpreting since 2006. She works as a freelance interpreter in the Canary Islands. As a PhD student, her main research topics include didactics of Community Interpreting and Telephone Interpreting. 